\title{
ANALYSIS OF NATURAL AND MAN-MADE THREATS FOR REGIONAL SECURITY IN UKRAINE
}

\author{
Sergiy Ivanyuta \\ Department of Energy and Technological Security \\ National Institute for Strategic Studies \\ 13 Chokolivskiy blvd., Kyiv, Ukraine, 03186 \\ ivanyuta@niss.gov.ua
}

\begin{abstract}
During the study the regions of the state have been considered as a multi-dynamic system with complex large-scale communications both within individual levels and between all levels. The main elements of region protection including population, industrial objects and environment were used for the analysis of functions of regional security. As such it was suggested that risk analysis at the regional level is closely linked with an analysis of threats which determine the level of region's security. The theoretical basis of evaluation of the security regions can be associated with the reliability theory in terms of emergencies which should be considered as a failure of the substantial elements that lead to the violation of their sustainability. The methodology for assessing levels of region's security of the state with the use of reliability theory to analyze the impact of natural and man-made threats to the protection of the main objects of the region including the components of the environment, objects and people is anticipated. This provides the opportunity to carry out a comparative analysis of regional ecological security, scientific substantiate an acceptable level of risk for each of them, as well as effectively allocate available funds to prevent negative consequences of threats between regions. On the basis of described methodology the assessment of natural and man-made threats of regional security of the Ivano-Frankivsk region of Ukraine is carried out. The hypothesis that the consequences of various emergencies at regional level are distributed on Poisson law is tested with the use of Pearson criteria. The dynamics of change of volumes of deficiency of gross regional product as a result of losses from the emergencies of different origin is analyzed. The proposed methodology for assessment of region's security levels will allow more reasonably determine the acceptable level of risk of emergency for each of them, effectively allocate the available material and financial resources between regions to prevent the negative consequences of emergency. In general it will provide tangible improvement for the security of population, industrial objects and the environment in the conditions of various emergencies of different origin possible in the state.
\end{abstract}

Keywords: natural and man-made threats, regional security, emergency situations, risk, sources of threats, economic losses.

\section{Introduction}

Condition of state's environmental security is largely determined by the efficiency of regional policy, which provides assurance for security of population, industrial objects and the environment from the destructive influence of the whole spectrum of natural and man-made threats. One of the important reasons for deficient security management regions of the state is inefficient and outdated environmental monitoring system that does not meet modern requirements.

About 250 emergency situations of different origin are occurred in Ukraine annually, due to which the state may expend significant financial resources up to $2.5 \%$ of gross domestic product for localization and liquidation of their consequences. This can be an additional factor in the worsening of socio-economic situation and the loss of a meaningful real opportunity to improve the standard of living of citizens. Analysis of current trends of economic damage from natural and man-made disasters around the world and in Ukraine indicates a high likelihood of emergency situations of natural and man-made character with significant risk to the public and the state in case of implementation $[1,2]$.

The positive experience of developed countries shows that overcoming the negative trends of growing losses and costs as a result of emergencies of various origins may be achieved on the basis of complex analysis and risk management within the national system of regulation and public security areas. The basis of this system should be an analysis of possible natural and man-made threats to regional security. 
Each region is a complex of socio-economic and ecological systems, operation of which is characterized by unstable equilibrium due to influence of significant number of political, economic, and environmental factors. An important feature of this condition is the rapid appearance and development of economic and environmental crisis phenomena influenced by external disturbances due to the inability of the region to confront the destabilizing effect. Given the export orientation of the economy of Ukraine with predominant direction for extraction and processing of large amounts of minerals, resulting in significant pollution and degradation of air, land, water sources in many regions of the state, a transition to an unstable state is possible because of the influence of environmental factors.

Regional security characterizes such a state of region's protection at which it is able to withstand the destabilizing effects of internal and external threats, and its operation does not create threats to the region and the elements of the environment. The methodical approach to the analysis of actual natural and man-made threats to regional security is anticipated further.

\section{Analysis of published data and problem definition}

Investigation of expression of natural and man-made threats around the world revealed that risk of its circulation has a tendency to increase in the near future [1, 3]. Analysis of UN and the World Bank official data on inclinations of environmental treats showed a substantial increase of losses from natural disasters in many European countries [4, 5]. The main approaches for analysis of damage from realization of natural and man-made threats in Ukraine [6, 7] and worldwide [8, 9] are analyzed. Taking into account the negative consequences of emergencies of natural and technological origin with regard to global climate change $[10,11]$ we can conclude the need to clarify results of inclusive analysis of natural and man-made threats for regional security in Ukraine.

The aim of this research is development of methodical approach to analysis of natural and man-made treats for regional security realization of which could lead to increasing the risk of economic losses and devastating negative consequences for population, infrastructure and environment.

In order to achieve the goal of this research the following specific tasks have been established:

- analysis of current natural and man-made threats for regional security of Ivano-Frankivsk region in Ukraine;

- development of methodology for analysis of region's security level taking into account the dimension of various threats to environment;

- investigation of region's security functions for main elements of protection including population, industrial objects and environment;

- analysis of dynamics of the volume of gross regional product shortfall due to losses from emergency situations of different origin.

\section{Materials and Methods}

The study area covers the territory of Ukraine, geological structure of which is determined by its location in the southwestern part of the East European platform and partially in the mountainous regions of the Carpathians and the Crimea. Significant changes of physical and mechanical properties of soils resulted in the change of groundwater regime and development of flooding across the most regions of the country $[2,12,13]$.

The various data on natural and technological treats distribution across the country including tables, maps from the Ministry of environment and State Service for Emergencies of Ukraine were used for analysis.

Risk analysis at the regional level closely linked with an analysis of threats, which in turn determine the level of region's security in the state. The theoretical basis of evaluation of the security in regions can be associated with the reliability theory in terms of emergencies which should be considered as a failure of the substantial elements that lead to the violation of their sustainability.

Region's security is determined by the risk which does not exceed acceptable levels. Denote $\mathrm{S}_{\Sigma}(\mathrm{t})$ as a security function whereas set of characteristics for accidents and disasters with the potential level is determined by using the risk of functions $H_{\Sigma}(t)$. 
When calculated it is believed that emergency situations (ES) with negative consequences for the protection of basic objects of the region are distributed by the Poisson law.

$$
\mathrm{F}(\mathrm{N})=\mathrm{P}(\xi \leq \mathrm{N})=\sum_{\mathrm{k}=0}^{\mathrm{N}} \mathrm{P}(\mathrm{k})=\sum_{\mathrm{k}=0}^{\mathrm{N}} \frac{1}{\mathrm{k} !} \mathrm{a}(\Delta \mathrm{t})^{\mathrm{k}} \exp (-\mathrm{a}(\Delta \mathrm{t}))
$$

where $\xi$ - random number of ES implementations for the time $\Delta \mathrm{t} ; \mathrm{P}(\mathrm{k})$ - probability of $\mathrm{k}$ ES for the time $\Delta \mathrm{t} ; \mathrm{a}(\Delta \mathrm{t})$ - parameter of the Poisson distribution which is defined as the average number of emergencies over time $\Delta \mathrm{t}, \mathrm{a}(\Delta \mathrm{t})=\mathrm{M}[\xi]=\lambda \Delta \mathrm{t} ; \lambda$ - ES frequency for unitary time interval; N - ES amount for the period of time $\Delta \mathrm{t}$.

Evaluation of emergency frequency ratio $\lambda$ is calculating by expression $\lambda=N / \Delta T$, where $\mathrm{N}-$ amount of ES for the period $\Delta \mathrm{T}>\Delta \mathrm{t}$.

Then $[6,14,15]$

$$
\begin{gathered}
\mathrm{S}_{\Sigma}(\mathrm{t})=\exp \left(-\sum_{\mathrm{i}}^{\mathrm{n}} \int_{0}^{\mathrm{t}} \lambda_{\mathrm{i}}(\tau) \rho_{\mathrm{ij}}(\tau) \mathrm{d} \tau\right), \\
\mathrm{H}_{\Sigma}(\mathrm{t})=1-\exp \left(-\sum_{\mathrm{i}}^{\mathrm{n}} \int_{0}^{\mathrm{t}} \lambda_{\mathrm{i}}(\tau) \rho_{\mathrm{ij}}(\tau) \mathrm{d} \tau\right),
\end{gathered}
$$

where $\mathrm{S}_{\mathrm{i}}, \mathrm{H}_{\mathrm{i}}$ functions of security and risk for $\mathrm{i}$ threat, $\mathrm{n}$ amount of threats; $\lambda_{i}$ - intensity of $\mathrm{i}$ kind emergencies; $\rho_{\mathrm{ij}}$ - probability of $\mathrm{j}$ system component for $\mathrm{i}$ kind of emergency.

Calculation of probabilities $\rho_{\mathrm{ij}}$ demands availability of technical, environmental, economic and social security criteria that could be determined by the first approximation.

$$
\rho_{\mathrm{ij}}=\frac{\mathrm{n}_{\mathrm{ij}}}{\mathrm{n}_{\mathrm{i}}}
$$

where $n_{i j}$ - amount of $i$-type ES with affection of $j$-component, $n_{i}$ - total amount of $i$-type events. $\lambda_{\mathrm{i}}$ and $\rho_{\mathrm{ij}}$ parameters are calculated using statistical estimation methods for each i-type.

To test the hypothesis on change of random variable - number of losses $\mathrm{k}$ from emergencies for basic protection objects in particular region by Poisson distribution with significance level $\alpha=0,05$ the value of Pearson criterion $\chi^{2}$ is calculating

$$
\chi^{2}=\sum_{\mathrm{k}=1}^{\mathrm{r}} \frac{\left(\mathrm{n}_{\mathrm{k}}-\mathrm{n}_{\mathrm{k}}^{\prime}\right)^{2}}{\mathrm{n}_{\mathrm{k}}^{\prime}}=\sum_{\mathrm{k}=1}^{\mathrm{r}} \frac{\left(\mathrm{n}_{\mathrm{k}}-\mathrm{Np}_{\mathrm{k}}\right)^{2}}{\mathrm{~Np}_{\mathrm{k}}},
$$

where $n_{k}$ - empirical probability of ES with negative consequences for the basic objects of protection for particular region, $\mathrm{n}_{\mathrm{k}}^{\prime}$ - theoretical probability defined as the composition of total amount of ES $\mathrm{N}$ and theoretical likelihood of emergency $\mathrm{p}_{\mathrm{k}}$ with negative consequences in a given region; $\mathrm{r}$ - maximum number of cases with observed losses $\mathrm{k}$ from emergencies at regional level.

\section{Experimental procedures}

Estimation of average probability of emergencies in Ivano-Frankivsk region is carried out

$$
\lambda \simeq \overline{\mathrm{x}}=\sum_{\mathrm{k}=1}^{\mathrm{r}} \mathrm{n}_{\mathrm{k}} \mathrm{k} / \mathrm{N}=4,644 .
$$

Herewith theoretical likelihood of emergency with negative consequences for the main objects of region's protection for the conditions of Poisson distribution is determined

$$
\mathrm{p}_{\mathrm{k}}=\mathrm{P}_{\mathrm{n}}(\mathrm{k})=\frac{\lambda^{\mathrm{k}}}{\mathrm{k} !} \mathrm{e}^{-\lambda}=\frac{4,644^{\mathrm{k}} \mathrm{e}^{-4,644}}{\mathrm{k} !},
$$

where $\lambda$ is a sample mean that for the current conditions is specified $\lambda=4,644 ; \mathrm{k}-$ the amount of losses from emergency for the main objects of protection of specified region. Results of calculation of Pearson criterion are given in Table 1. 
Table 1

Parameters of Pearson criterion calculation

\begin{tabular}{|c|c|c|c|c|}
\hline $\mathbf{k}$ & $n_{k}$ & $\mathbf{p}_{\mathrm{k}}$ & $n_{k}^{\prime}=N p_{k}$ & $\left(n_{k}-n_{k}^{\prime}\right)^{2} / n_{k}^{\prime}$ \\
\hline 0 & 1 & 0,009618 & 1,702473 & 0,289854 \\
\hline 1 & 6 & 0,044669 & 7,906399 & 0,459673 \\
\hline 2 & 18 & 0,103723 & 18,35893 & 0,007017 \\
\hline 3 & 25 & 0,160565 & 28,42004 & 0,411563 \\
\hline 4 & 29 & 0,186419 & 32,99614 & 0,483971 \\
\hline 5 & 48 & 0,173148 & 30,64727 & 9,825258 \\
\hline 6 & 21 & 0,134019 & 23,72133 & 0,312194 \\
\hline 7 & 15 & 0,088913 & 15,73764 & 0,034574 \\
\hline 8 & 9 & 0,051615 & 9,135834 & 0,00202 \\
\hline 9 & 4 & 0,026634 & 4,714159 & 0,10819 \\
\hline 10 & 1 & 0,012369 & 2,189288 & 0,646057 \\
\hline$\Sigma$ & 177 & 0,991692 & 175,5295 & 12,58037 \\
\hline
\end{tabular}

The evaluation results indicate that the actual value of the criterion is $\chi^{2}=12,580$. Critical value of Pearson criterion for significance level of 0.05 and 9 degrees of freedom (for the condition of Poisson distribution the amount degrees of freedom $r=k-2=11-2=9$ ) is estimated as $\chi_{0,05 ; 9}^{2}=16,918$. Since the actual value of $\chi^{2}$ does not exceed a critical one, i. e., hypothesis regarding the distribution for parent population of number of losses from emergencies to main objects of protection of Ivano-Frankivsk region by Poisson law does not contradict to experimental data.

Statistical evaluation of emergencies intensity $\lambda_{\mathrm{i}}$ and probability of affection $\rho_{\mathrm{ij}}$ are given in Table 2.

Table 2

Characteristics of emergencies in Ivano-Frankivsk [6]

\begin{tabular}{|c|c|c|c|c|}
\hline \multirow{2}{*}{ Type of emergency } & \multirow{2}{*}{$\lambda_{i} \cdot 10^{-4}, 1 /$ year } & \multicolumn{3}{|c|}{$\boldsymbol{\rho}_{\mathrm{ij}}$} \\
\hline & & Population & Objects & Environment \\
\hline Fires, explosions & 0,86 & 0,3 & 0,5 & 0,2 \\
\hline Accidents on power systems & 0,86 & 0,2 & 0,6 & 0,2 \\
\hline Failures (disaster) on transport & 0,95 & 0,3 & 0,4 & 0,3 \\
\hline Infectious disease & 1,05 & 0,9 & 0 & 0 \\
\hline Hydrological ES & 1,71 & 0,1 & 0,25 & 0,65 \\
\hline Poisoning & 2,28 & 0,9 & 0 & 0 \\
\hline Meteorological ES & 6,56 & 0,2 & 0,15 & 0,65 \\
\hline
\end{tabular}

These tables show that emergencies of Ivano-Frankivsk region belong to the class that repeated with a small probability. The results of evaluation of intensity $\lambda_{i}$ indicate that the greatest threat to all objects of protection in region comes from meteorological ES which have the highest 
intensity value $\left(6.56 \cdot 10^{-4} 1 / \mathrm{h}\right.$.) among all other types of emergency, possible in the region. After meteorological ES the greatest intensity in region have such type of emergencies as poisoning, hydrological ES and infectious diseases.

Analysis of data on the probability of damage $\rho_{\mathrm{ij}}$ of three main objects of region protection indicates that for such criterion the biggest threat for the person comes from infectious diseases and poisoning of people (the probability of damage is 0.9 ) as well as fires, explosions. The most dangerous for industrial objects by that criterion are fires, explosions, accidents on transport as well as the accidents at the power systems. The highest environmental treats are hydrological and meteorological ES for which the probability of damage is 0.75 .

Security features $S_{\Sigma}(t)$ for the objects of protection for Ivano-Frankivsk region, which were calculated according to Table 2 are shown in Fig. 1.

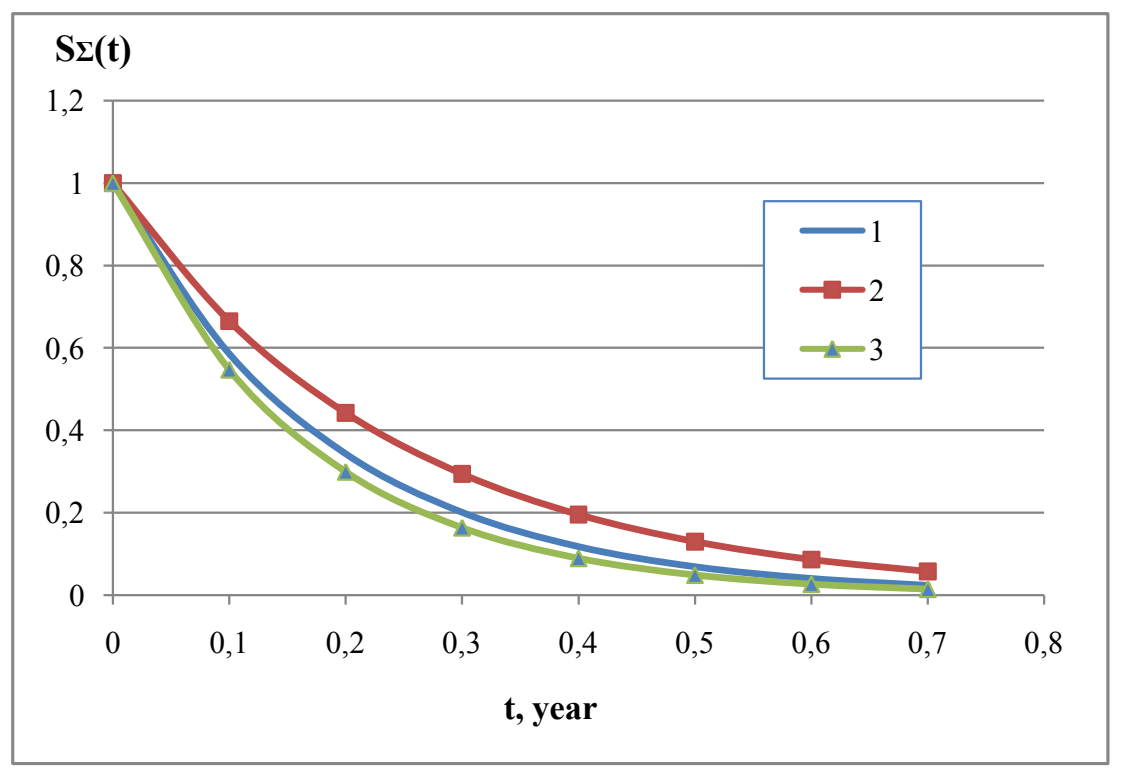

Fig. 1. Security functions for objects of protection for Ivano-Frankivsk region [6]: 1 - population; 2 - industrial facilities; 3 - environment

The analysis of security functions suggest that the level of security for people and the environment in Ivano-Frankivsk region have relatively similar values, while the level of security of industrial facilities differs significantly toward improving. Data in Fig. 1 shows that acceptable levels of security (when $S_{\Sigma}(t) \geq 0.8$ ) during the year for people and the environment are provided only for 15 days. It should also be noted that the most secure element for Ivano-Frankivsk region is the industrial facilities acceptable level of security for which can be expected within 20 days. Given the extremely low duration of the safe operation for elements of region's objects of protection it is clear that the calculated values of security levels are insufficient.

\section{Results}

For the territory of Ukraine most typical emergencies are accidents in industrial, civil and military facilities related to the loss of credibility and stability of structures; accidents on transport; fire, explosions at industrial sites; fire in natural ecosystems; accidents with the release of hazardous chemicals at the sites; meteorological emergencies; geological emergencies; poisoning people; infectious diseases of people $[4,5,12]$.

\section{1. Identification of natural and man-made threats to the security of the Ivano-} Frankivsk region

According to the State service for emergencies of Ukraine the region hosted more than 500 objects of chemical, power, oil, timber and other industries. More than $4 \%$ of region's territory 
is employed by oil and gas pipelines. There are 134 treatment plants, 30 large landfills handling of solid waste, tailings and landfills of industrial waste are located.

The most important natural threats in the Ivano-Frankivsk region are dangerous exogenous geological processes, phenomena of hydrological and hydro meteorological origin, fire in natural ecosystems, biomedical emergencies and more.

Geological threats in region are manifested in the form of landslides, karst processes and flooding. According to the State service for emergencies of Ukraine, more than 600 landslides with total area of $477 \mathrm{~km}^{2}$ and karst events have been identified on the $38 \%$ of the region's territory [2]. Landslides are most common in Kosovo and Verkhovyna areas while natural karst is distributed in Tlumach, Horodenka, Sniatyn areas. In addition, most part of the Ivano-Frankivsk region is affected by seismic danger.

Among meteorological threats in the region the most common are heavy rains, strong winds and a strong storm. The emergence of these phenomena often leads to the destruction and damage of buildings, power abuse and communications.

There is a risk of fire in natural ecosystems in the region. According to the State service for emergencies of Ukraine the area of the zone of their possible distribution is around 700 thousand ha including.

Threats of medical and biological nature in the region are caused due to the presence of epizootic and epidemic danger zones of anthrax infection, leptospirosis tetanus and tularemia.

Man-made threats to the Ivano-Frankivsk region are triggered due to the presence over 300 potentially hazardous objects on its territory among which are dominated industries, hydraulic structures, tunnels, quarries, pipelines, bridges, overpasses [13].

Radiation security of region is largely determined by the productive activity of more than 130 objects that use sources and instruments for ionizing radiation.

Chemical security of Ivano-Frankivsk region is caused by the presence of 31 dangerous chemical facilities which houses about 10 thousand ton of chemically hazardous substances. According to expert estimates about 800 thousand people can get in area of possible chemical contamination in the case of emergencies. The largest chemical threat in the region is LLC "Karpatnaftokhim", which is stored and used in the production of more than 2,000 tons of chlorine and about 6,000 tons of other hazardous chemicals [2]. Significant threat to region's security also create various objects of state enterprise "Potassium Plant" JSC “Oriana” including mines, Dombrowski quarry dumps saline soils, tailings and tailings pond.

The hydrodynamic security area is largely determined by the presence of two reservoirs, tailings and sludge storage. While total design capacity of tailings and sludge storage is 32.7 million $\mathrm{m}^{3}$ the actual amount of accumulated substances has already approached the threshold. The region's territory runs rivers with a total length of 15 thousand $\mathrm{km}$ most of which needs urgent improvement of waterproof dams and shore facilities.

The networks of gas and product pipelines are going through the territory of region. Much of the threats are caused by the influence of dangerous exogenous geological processes that in the case of activation can significantly complicate the operation of pipelines due to damage of critical structural elements and weakening of rocks background.

Using GIS technology the spatial assessment of impact from hazardous geological processes on the security of main gas pipelines Ivano-Frankivsk region is implemented (Fig. 2).

Evaluation results show that many of the networks is likely in areas of karst manifestations (52\%), a small portion is in danger of landslides $(7,3 \%)$, which adversely affects the efficiency of the operation and is an additional factor in the deterioration of traffic security area.

Threats to critical infrastructure area are caused due to large depreciation of equipment in the system utilities. In particular, there is urgent need to upgrade the treatment for plant water supply, pumping and compressor plants. Much of the area sewage networks do not meet modern requirements and is characterized by a significant level of clogging of reservoirs. 




Fig. 2. Impact of exogenous geological processes on the security of gas pipelines in Ivano-Frankivsk region

\section{2. Evaluation of natural and man-made threats to regional security of Ivano- Frankivsk region}

According to the State service for emergencies there were 177 emergencies of natural and made-made origins in Ivano-Frankivsk region during 2002-2013 in which 115 people died and 685 were injured [2]. Dynamics of emergency situations change and share of Ivano-Frankivsk region's in total amount of ES in Ukraine is presented in Fig. 3.

These data indicate that during the last 3 years there was a definite decrease in the number of emergency in the Ivano-Frankivsk region. For the territory of Ivano-Frankivsk region the most typical are meteorological ES, poisoning people, hydrological ES, infectious diseases, catastrophe in transport, and accidents in electric power systems, fires, and explosions.

In this context, it is advisable to consider a number of indicators characterizing economic losses as a result of emergency of different origin in the region. 
Among them the most important is share index of shortfall in gross regional product (GRP) due to losses from the emergencies, whose value is calculated as the ratio of annual losses from emergency to annual GRP of Ivano-Frankivsk region (Fig. 4).

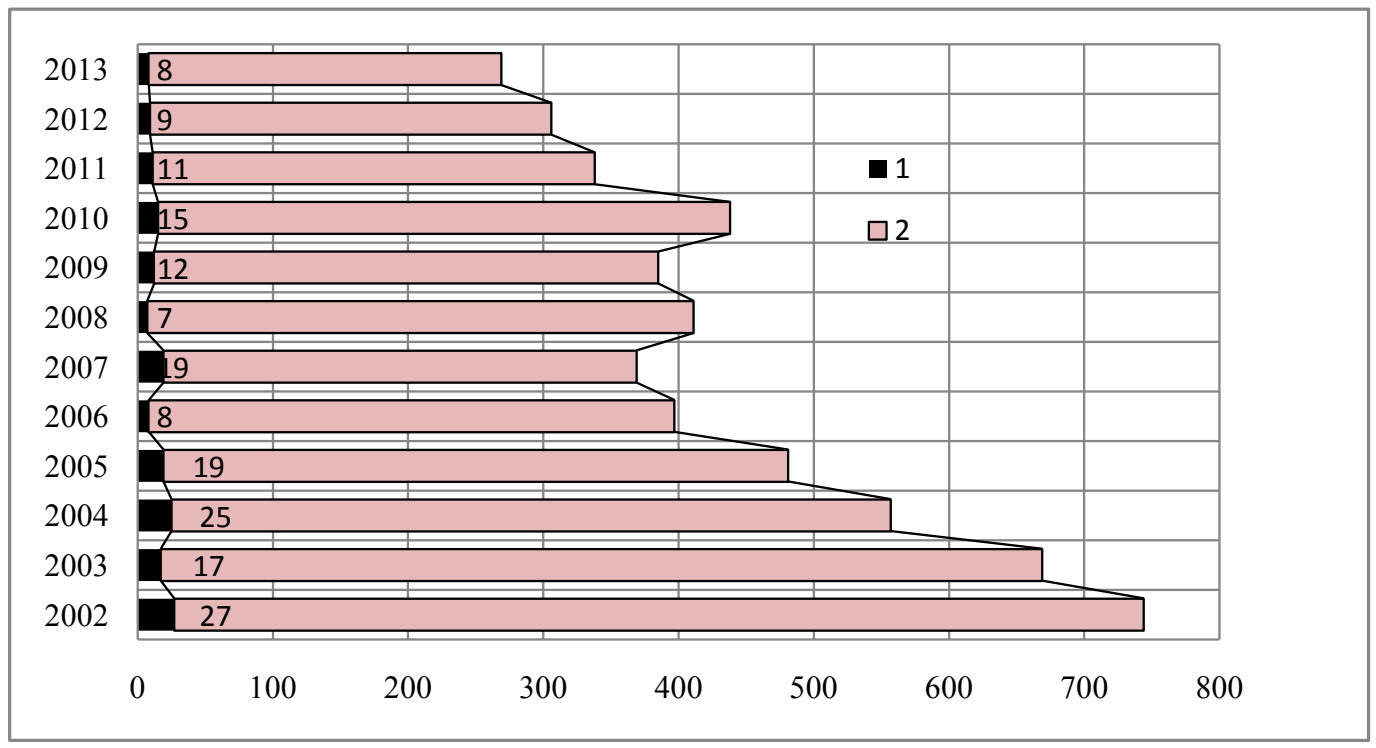

Fig. 3. Share of Ivano-Frankivsk region in the total number of emergency in Ukraine: 1 - Amount of ES in Ivano-Frankivsk region; 2 - Amount of ES in Ukraine

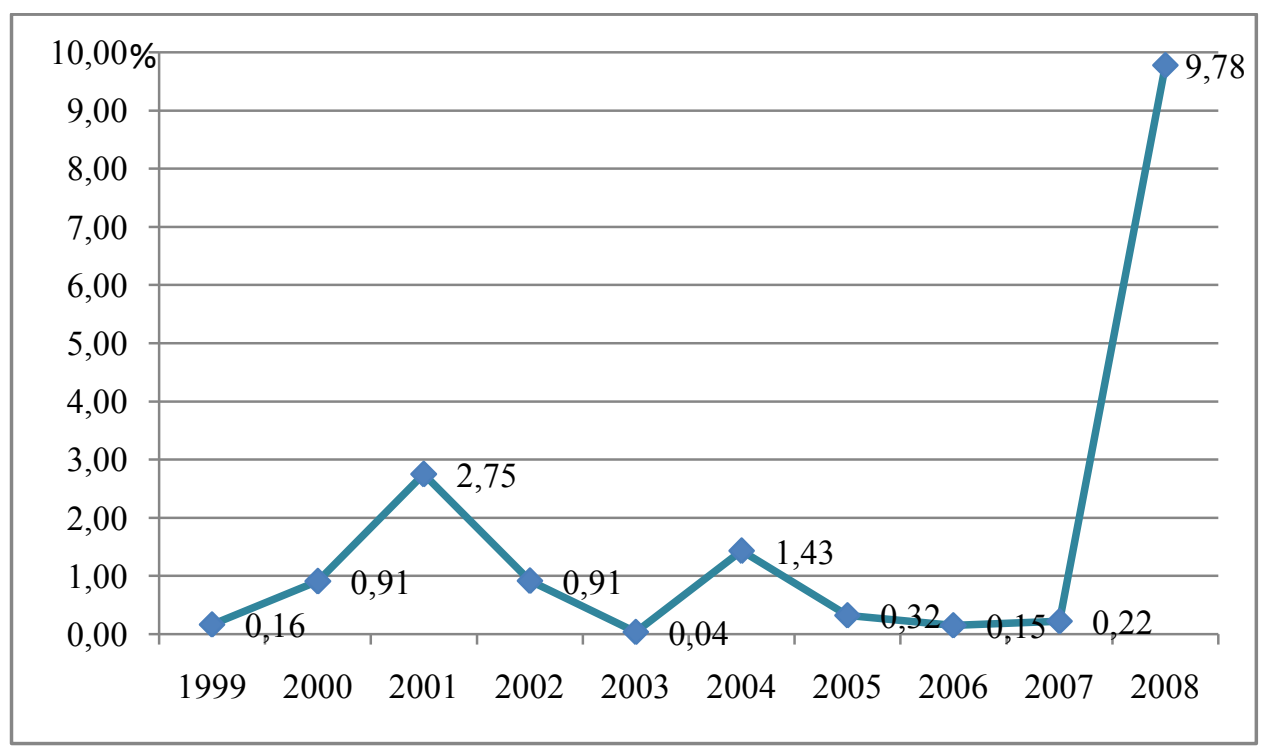

Fig. 4. Dynamics of the share of GRP shortfall due to losses from emergency situations in Ivano-Frankivsk region

The analysis of this indicator indicates that at some point losses from emergency situations in the region may lead to the loss of about $9.78 \%$ of GRP (2008), which can be a significant negative factor deteriorating socio-economic situation in the region. Obviously, the extremely high value of this indicator in 2001 and 2008 is caused by the severe consequences of the disastrous floods in the Carpathian region the scope of which has been reached to level of threats to national security $[2,6]$.

For a more complete definition of the connection between the ES intensity and the level economic losses the dynamics of changing economic risk components of emergency in Ivano-Frankivsk region is studied (Fig. 5). 


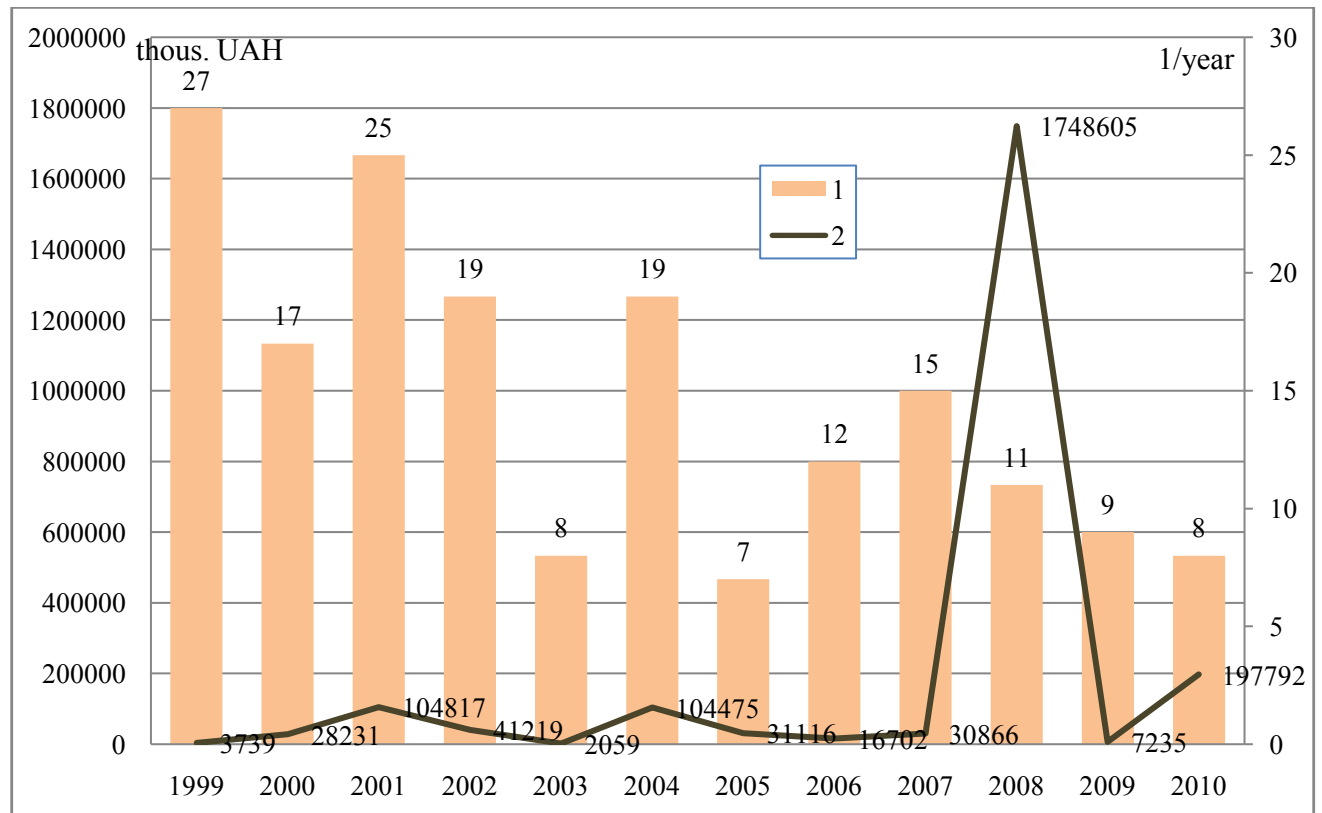

Fig. 5. Dynamics of intensity of emergency situations and economic losses after them in Ivano-Frankivsk region: 1 - ES intensity, 1/year; 2 - Economic losses after ES, thousand UAH

The results indicate a matching between increase in economic losses from emergency situations and appreciable increase in annual intensity of emergency in 2001 and 2004. The opposite trend observed in 2008 and 2010 when there was an increase in economic losses from emergency situations while reducing their intensity.

In general it can be argued that during the last years in Ivano-Frankivsk region was a definite increase in the amount of losses from emergency compared to 2009 mainly due to vast negative consequences of catastrophic flooding. At the same time there is a possible trend towards increasing losses in subsequent years with a decrease in the intensity of emergency situations of natural origin in the region.

\section{Discussion}

The priority task of the state policy in the field of protection of population, industrial facilities and territories from emergency situations of different nature is providing of guaranteed level of security for individuals, society and the state which corresponds to developed countries. Effective solution to this problem is located in the sphere of disaster risk reduction, decreasing unproductive losses and costs of the liquidation of their consequences $[15,16]$. This requires complex analysis of actual natural and man-made threats, constant monitoring of their implementation and development on this basis of reasonable precautionary measures to prevent the threats, implementation of which can lead to significant negative consequences.

Evaluation results of natural and man-made threats to regional security of Ivano-Frankivsk region indicate that any object of region's protection including population, industrial facilities and environment can't be provided with an adequate level of security over time that exceeds 15 days. However, the data showed that among the three main elements of region's protection the most secure is environment and least protected is population. Overall the analysis showed that the current state of natural and technological security of Ivano-Frankivsk region practically does not meet the required level when the region is able to successfully confront the destabilizing effects of external and internal threats and does not create additional threats to itself and the environment.

\section{Conclusions}

The methodology for assessing levels of region's security with the use of reliability theory to analyze the impact of natural and man-made threats to the protection of the main objects of the region including the components of the environment, objects and people is anticipated. This pro- 
vides the opportunity to carry out a comparative analysis of regional ecological security, scientific substantiate an acceptable level of risk for each of them, as well as effectively allocate available funds to prevent negative consequences of threats between regions.

On the basis of defined methodology the assessment of natural and man-made threats of regional security of the Ivano-Frankivsk region of Ukraine is carried out. The hypothesis that the consequences of various emergencies at regional level are distributed on Poisson law is tested with the use of Pearson criteria. The dynamics of change of volumes of deficiency of gross regional product as a result of losses from the emergencies of different origin is analyzed.

The proposed methodology for assessment of region's security levels will allow more reasonably determine the acceptable level of risk of emergency for each of them, effectively allocate the available material and financial resources between regions to prevent the negative consequences of emergency. Methodical approach to the assessment of natural and man-made threats that was anticipated in the study provides the ability to perform a comparative analysis of natural and manmade security of administrative regions. This will allow more reasonably determine the acceptable level of risk of emergency for each region, effectively allocate the available material and financial resources between them in order to prevent the negative consequences of emergency. In general, this will provide tangible improvement to the security of population, industrial facilities and the environment in terms of emergencies of different origin possible in the state.

\section{References}

[1] Global Risks Report (2015). [online]. Available from: http://reports.weforum.org/global-risks-2015/

[2] National Report on the State of Technological and Natural Safety in Ukraine (2013). Available at: http://mns.gov.ua/content/annual_report_2013.html

[3] Farah, P. D. (2015). Sustainable Energy Investments and National Security: Arbitration and Negotiation Issues. Journal of world energy law and business, 8 (6), 34-49. doi: 10.1093/jwelb/jwv036

[4] Wallensteen, P., Swain, A. (1997). Environment, Conflict and Cooperation. The Global Environment. Science, Technology and Management, 2, 691-704. doi: 10.1002/9783527619658.ch41

[5] Ehrlich, P. R., Ehrlich, A. H. (1988). The Environmental Dimensions of National Security. Stanford, CA: Stanford Institute for Population and Resource Studies.

[6] Ivanyuta, S., Kachinskiy, A. (2012). Environmental natural and technologic safety of Ukraine: regional dimension of threats and risks. National Institute for Strategic Studies, 308.

[7] Bychenok, M., Ivanyuta, S., Yakovlev, E. (2008). Risks of life activity in natural and technogenic environment. Intertechnology, 160.

[8] Gleick, P. H. (1991). Environment and security: The clear connections. Bulletin of the Atomic Scientists. 47 (3), 16-21. doi: 10.1080/00963402.1991.11459956

[9] Gleick, P. H. (1990). Environment, resources, and international security and politics. In E. Arnett (ed.) Science and International Security: Responding to a Changing World. American Association for the Advancement of Science Press, Washington, D. C., 501-523.

[10] Lepikhin, A. (1993). Security Region: statistical evaluation and forecast. Problems of safety in emergency situation, 9, 92-101.

[11] Danylyshyn, B. (2008). Safety of Regions in Ukraine and the strategy of its guarantee, Science opinion, 1, 392.

[12] Ivanyuta, S. (2015). Development of risk assessment methodology for emergency losses in the regions of Ukraine. Eastern-European Journal of Enterprise Technologies, 3 (6), 48-53. doi: 10.15587/1729-4061.2015.43070

[13] Ivanyuta, S. (2015). Assessment of threats from exogenous geological processes to safety of international transport corridors in Ukraine. Science \& Military Journal, 1 (1), 39-42.

[14] Dodds, F. Pippard, T. (2005). Human and Environmental Security: An Agenda for Change. London, Earthscan, 1, 61-74.

[15] Barlow, R. (1984). Statistical theory of reliability and test reliability, Science, 327.

[16] Myers, N. (1986). The Environmental Dimension to Security Issues. The Environmentalist, 6, 251-257. doi: 10.1007/bf02238056 